\title{
Regional Disparity in Cropping Intensity and Relative Impact of Irrigation in Haryana
}

\author{
Dr. Vanita Ahlawat ${ }^{1,}$ Renu $^{2}$ \\ ${ }^{I}$ Assistant Professor, Haryana School of Business, G J U S \&T, Hisar \\ ${ }^{2}$ Research Scholar, Haryana School of Business, G J U S\&T, Hisar,
}

\begin{abstract}
Agricultural development ofa state can be obtained through intensifying the crops at limited area. Higher cropping intensity indicates maximum area is cropped more than once. The presentstudy is an attempt to analyse district wise performance in intensity of cropping in Haryana. Further the impact of irrigation on cropping intensity is analysed. The data is taken from various issues of Statistical Abstracts of Haryana. Appropriate statistical tools i.e. average; variance and simple linear regression are used for analysis of data. Variations were found among the districts in terms of cropping intensity.Panipat and Karnal districtwerehighest performers in intensifying crops while Gurgaon,Jhajjar and Rewari were the poor one.Moderate performance was observed in Fatehabad and Sirsa district. This variability may exist due to rainfall, irrigation facilities, environmental and agro climatic differences in the regions and adoption of modern agricultural techniques. Irrigation facility is found to have significant impact on cropping intensity across the districts. Hence it is found to be a good predictor of cropping intensity. Thus improved irrigation facilities will enhance the cropping intensity as well.
\end{abstract}

Keywords: Cropping intensity, Disparity, Interdistrict,Agriculture

\section{Introduction}

Development of an economy is determined by efficient utilisation of the scarce resources of its society. Land is one of the limited resources which are overburdened by continuously increasing population. Problem ofShortage of food grain in country can be overcome through proper utilisation of land under cultivation. Haryana is the second largest contributor of food grain in India Rice-wheat and cotton-wheat rotation system is dominantly prevalent in Haryana Such a large contribution to food grain is possibly maintained through procuring many crops at the limited area sown. Cropping intensitydetermine the number of crops availed from net area sown in a particular agricultural year. Higher cropping intensity indicates that larger part of sown area is cropped more than once (Kalaiselvi \& Sundar, 2011).Cropping intensity of Haryana is $181.47 \%$ in 2014. It was comparatively much larger than the overall cropping intensity of India i.e.140.5\%.The enhancement in cropping intensity is possible due to availability of better irrigation facilities and increased use of new agricultural technologies(Singh, 1990).Intensification in crops and use of HYV (High Yielding Variety) seeds and fertilisers since green revolution has increased food grain production in Haryana. Increased food grain reduced the dependence of the state on import and further, extended the exports of food grain.Haryana is divided in to three agro-eco regions. These regions vary with regard to development oftheir irrigation facilities and other agricultural infrastructure. Study on disparities in cropping intensity among different districts will provide more clear view of variations within regions.The present paper will identify the inter-district disparities in cropping intensity in Haryana. Increase in cropping intensity indicates increased agricultural developmentof region(Singh,2015). Hence present study of cropping intensity will provide insight about the agricultural development at district level.A district level study on cropping intensity is important to know the agricultural disparity within the state and to take measures to ensure sustainedand equalised agricultural growth at district level. Further the impact of irrigation on cropping intensity will highlight to the extent to which intensification of crops be improved by ensuring better irrigation facilities at government and individual level.

\section{Review of Literature}

Aggarwal and Moudgil (2015) concluded that cropping intensity, irrigation intensity and crop yield and density of tractors had increased since green revolution but the contribution of agriculture to Haryana's GDP had declined over the years. Govt. should make efforts for agriculture development.Singh (2015)foundthat highest cropping area was covered by wheat and rice respectively. In contrast, maize,jowar and barley covered lowest cropping area. Further the cropping intensity of Haryana had increased over the years. All districts had achieved above average cropping intensity except some few districts.Hazare et al. (2014)revealed in their study that cropping intensity ofKohlapur district has increased through crop diversification. Authors concluded that cropping pattern had shifted to commercial crops. The shift in the pattern of cropping was influenced by improvement in irrigation and market facilities.Kumar and Jain (2013)highlighted in their study the district wise 
disparity in agricultural productivity in India. Authors concluded that variations were due to differences in rainfall, resources for irrigation and use of modern agricultural techniques. Raman and Kumari (2012) identified the region as well as district wise disparity in agricultural development of Uttar Pradesh. Authors found that central and western region were best performer while Budelkhand and Vindhyan zone lacked behind in the agricultural development.Singh (2012)revealed that the application of modern agricultural inputs had enhanced the cropping intensity. Further, agricultural productivity wasincreased due to use of improved fertilizers, seeds and modern equipments. Author indicated that environmental and physical factors were responsible for regional variations in agricultural development.

Kalaiselvi and Sundar (2011) analysed the variations in cropping intensity in India and concluded that highest cropping intensity was found in states of northern region while lower cropping intensity were observed in dry regions depending on rainfall. Authors found the cropping intensity was dependent on irrigation facilities.Nag et al. (2009)found that Bikaner and Jaipur district had highest growth in cropping intensity while negative growth in cropping intensity was identified in Ajmer, Udipur and Bhilwara district. Authors further concluded that states with higher coefficient of variation (c. v.) experienced high fluctuation in rainfall and vice -versa. Panigrahy et al. (2004)identified that the cropping pattern in Bhatinda district was shifted towards ricewheat and cotton -wheat rotation. Authors found that intensity of cropping had increased over time due to enlargement of area under rice cultivation.Karunakaran and Palanisami (1998)found that cropping intensity had significant relationship with irrigation intensity in Tamil Nadu. Irrigation through dug well and tube well were found to had more positive relation with cropping intensity. Authors concluded that state should make more investment on irrigation facilities.

\section{Objective of the study}

The present study is conducted with the following objectives

$>$ To know district wise performance in intensification of cropping in Haryana.

$>$ To know the sub-period impact of irrigation facility on cropping intensity in Haryana.

\section{Research Methodology}

The present study is based on secondary data collected from various issues ofstatistical abstract of Haryana from 2005-06 to 2014-15.Cropping intensity is calculated for all the districts in Haryana from 2004-05 to 2013-14.Data for Mewat district is available since 2005-06 and for Palwal since 2008-09 as these are newly formed districts of Haryana. Relevant statistical tools such as growth rate, coefficient of variation (c. v.) and average is used for the purpose of analysis of data. While analysing impact of irrigation on cropping intensity, data for Mewat and Palwal are excluded from study as the data of these are not available for all the years under study. Simple linear regression method is used to show this impact.

Cropping Intensity and Irrigation Ratio is calculated by using the following formulas:

Cropping Intensity $(C I)=\frac{\text { TotalCroppedArea }}{\text { NetAreaSown }} \times 100$

Irrigation Ratio $(\%)=\frac{\text { Gross Irrigated Area }}{\text { Net Area Sown }} \times 100$

Haryana is an agriculturally developed state of India.Net sown area and gross cropped area of Haryana has increased since green revolution. Nearly $84 \%$ of cultivated area in Haryana has assured irrigation facility. Cropping intensity of Haryana was183.02 in 2013.It showed a growth rate of 2.15 percent from cropping intensity of 179.16 in 2004(Table 2).Higher cropping intensity means area is cropped more than once and viceversa. District wise average performance of cropping intensity in Haryana in can be categorised as:

Table 1: Categories of district wise performance in average cropping intensity (in \%)

\begin{tabular}{|l|l|l|}
\hline Below 170 & Low & Gurgaon, Mewat, Rewari, Jhajjar, Rohtak, Ambala,Yamunanagar \\
\hline $170-190$ & Moderate & Punchkula, Kurukshetra, Palwal, Mahendargarh, Sirsa, Fatehabad \\
\hline 190-above & High & Panipat, Karnal, Jind, Bhiwani, Sonipat, Hisar, Faridabad, Kaithal \\
\hline
\end{tabular}

Source: Summarised from Table 2 and classification as per Singh (2015)

In table 1, categorisation of districts is done on the basis of average cropping intensity of districts from 2004-05 to 2013-14. Districts having cropping intensity below 170\% are termed as low performing. While moderate performing districts have C.I. between $170 \%$ to $190 \%$ and high performing districts have C.I. above 190\%. (Singh, 2015) Further (Table 2) performance of districts within category is evaluated on the basis of their comparable growth rate and C.V. besides average cropping intensity. Among the low performing districts, Ambala district had highest average cropping intensity during the period under study i.e.169.61\%.Although Ambala experienced high variability (10.87\%)in intensifying crop over the period yet it had positive growth of $22.23 \%$. Hence its performance is satisfactory. Yamunanagar district was also performing well with average cropping intensity of $167.32 \%$ and positive growth rate of $3.29 \%$ and a meagre variation of $2.37 \%$. However 
Gurgaon had lowest average cropping intensity (i.e. 140.03\%) and a highly negative growth rate of $22.20 \%$ and variations during the analysis period were $9.42 \%$. Jhajjar had also low average cropping intensity i.e. $153.39 \%$ with high fluctuations (7.04\%) in cropping intensity and a positive growth rate of $12.07 \%$.

Among the moderate performing districts, Fatehabad district is performing better with highest average cropping intensity of $189.3 \%$ with slightly negative growth rate of $1.55 \%$ and variations of $1.54 \%$ in the analysis period of the study. Punchkula district had better position in intensification of crops with cropping intensity of $182.11 \%$.However a fluctuation of $8.02 \%$ in cropping intensity was observed during the study period. Still the performance was satisfactory. On the other hand, Sirsa district had been the lowest in average intensity of cropping i.e. $180.3 \%$ for the period under study. Although a positive growth $4.21 \%$ was observed yet fluctuation of $1.82 \%$ was found in cropping intensity during the study period. Similarly Mahendargarh district had been comparatively low in average cropping intensity (i.e. 180.53\%). However it experienced a positive growth rate of $15.37 \%$ with a variation of $5.06 \%$ during the period under study.

Among the high performing districts in intensification of cropping, Panipat district occupied highest position in average cropping intensity i.e. 199.17\%.Panipat showed a steady performance over the study period with zero growth rate and a small variation of $1.03 \%$. Karnal district was performing better with cropping intensity of $198.17 \%$ and a negative growth rate of $0.02 \%$ with a meagre variation of $2.09 \%$ was observed during the study period. Contrary to it, Kaithal district was comparatively low performer in terms of cropping intensity i.e. $190.09 \%$. It had observed a growth of $0.80 \%$ and variation of $1.36 \%$ in cropping intensity for the period under study. Similarly, Hisar district had average cropping intensity of $191.92 \%$. It showed a growth rate of $1.33 \%$ and a variability of $3.30 \%$ during the period under study.

There was disparity among Districts with regard to their intensification of cropping. Low performing districts had small average cropping intensity and were characterised by high variation with low or negative growth over the years. Moderate level districts had medium performance. While high performing districts had highest average crop intensity with steady or high growth rate and low fluctuations over the years. Gurgaon and Jhajjar districts has been lowest in cropping intensity which means that these districts are procuring comparatively a few crops during an agricultural year. Fatehabad and Sirsa district were medium performers in cropping intensity. On the other hand, Panipat and Karnal had highest performers in intensifying crops. Hence these districts have maximum area re-sown area under cultivation. In other words, all districts of Haryana have satisfactorily intensified their cropping area except Gurgon, Jhajjar, Rewari and Mewat.

Table 2: District wise cropping intensity (in \%) in Haryana and relative measures

\begin{tabular}{|c|c|c|c|c|c|c|c|c|c|c|c|c|c|}
\hline Districts & 2004-05 & $2005-06$ & $2006-07$ & $2007-08$ & $2008-09$ & $2009-10$ & $2010-11$ & 2011-12 & $2012-13$ & 2013-14 & $\begin{array}{l}\text { Growth } \\
\text { rate }\end{array}$ & C.V. & Average \\
\hline Ambala & 150.75 & 157.46 & 156.06 & 154.96 & 157.25 & 156.82 & 194.34 & 193.46 & 190.74 & 184.26 & 22.23 & 10.87 & 169.61 \\
\hline Panchkula & 191.30 & 195.83 & 191.67 & 175.00 & 195.83 & 162.50 & 158.33 & 168.00 & 191.30 & 191.30 & 0.00 & 8.02 & 182.11 \\
\hline Yamunanagar & 162.40 & 165.32 & 164.00 & 160.94 & 171.20 & 172.80 & 169.05 & 169.60 & 170.16 & 167.74 & 3.29 & 2.37 & 167.32 \\
\hline Kunukshetra & 184.67 & 180.67 & 177.33 & 182.67 & 182.67 & 188.67 & 168.32 & 182.78 & 175.50 & 185.03 & 0.20 & 3.20 & 180.83 \\
\hline Kaithal & 191.37 & 187.13 & 186.63 & 188.61 & 190.59 & 188.12 & 192.04 & 189.05 & 194.44 & 192.89 & 0.80 & 1.36 & 190.09 \\
\hline Kamal & 197.96 & 197.00 & 194.44 & 194.97 & 208.99 & 197.46 & 195.00 & 199.48 & 198.47 & 197.92 & -0.02 & 2.09 & 198.17 \\
\hline Panipat & 200.00 & 202.20 & 195.74 & 195.83 & 201.05 & 198.95 & 198.96 & 198.96 & 200.00 & 200.00 & 0.00 & 1.03 & 199.17 \\
\hline Sonipat & 189.12 & 202.72 & 182.28 & 190.32 & 194.19 & 194.12 & 213.89 & 186.98 & 188.16 & 192.05 & 1.55 & 4.66 & 193.38 \\
\hline Rohtak & 156.34 & 157.04 & 154.23 & 155.63 & 165.49 & 160.00 & 164.29 & 163.57 & 168.15 & 168.61 & 7.85 & 3.32 & 161.34 \\
\hline Jhajjar & 151.95 & 149.07 & 150.31 & 147.53 & 146.01 & 142.33 & 143.71 & 173.13 & 159.57 & 170.29 & 12.07 & 7.04 & 153.39 \\
\hline Fanidabad & 182.43 & 185.59 & 186.96 & 189.66 & 186.49 & 183.78 & 186.11 & 203.13 & 209.68 & 210.00 & 15.11 & 5.63 & 192.38 \\
\hline Palwal & n.a & n.a & n.a & n.a & 182.69 & 182.69 & 179.44 & 179.82 & 180.95 & 179.63 & $-1.68^{\wedge}$ & 0.83 & 180.87 \\
\hline Gurgaon & 174.55 & 125.51 & 144.05 & 138.10 & 137.35 & 139.29 & 139.02 & 137.04 & 129.63 & 135.8 & -22.20 & 9.42 & 140.03 \\
\hline Mewat & n.a & 156.03 & 163.91 & 170.45 & 160.75 & 161.68 & 163.21 & 147.01 & 148.57 & 169.52 & $8.65^{\wedge}$ & 5.15 & 160.13 \\
\hline Rewan & 151.59 & 155.65 & 173.21 & 157.94 & 157.60 & 152.38 & 156.35 & 154.76 & 145.60 & 151.59 & 0.00 & 4.61 & 155.67 \\
\hline Mahendragarh & 163.16 & 181.58 & 181.46 & 180.92 & 167.55 & 177.48 & 192.47 & 184.97 & 187.50 & 188.24 & 15.37 & 5.06 & 180.53 \\
\hline Bhiwani & 206.60 & 201.02 & 187.34 & 188.61 & 196.12 & 192.45 & 204.85 & 200.00 & 177.75 & 185.46 & -10.23 & 4.79 & 194.02 \\
\hline Jind & 181.32 & 201.72 & 200.00 & 201.28 & 195.83 & 196.22 & 198.74 & 200.84 & 196.65 & 197.49 & 8.92 & 3.01 & 197.01 \\
\hline Hisar & 196.19 & 203.51 & 188.55 & 185.04 & 189.47 & 182.53 & 193.09 & 192.47 & 189.49 & 198.80 & 1.33 & 3.30 & 191.92 \\
\hline Fatehabad & 195.37 & 187.56 & 188.44 & 188.00 & 189.29 & 185.27 & 190.18 & 188.39 & 192.34 & 192.34 & -1.55 & 1.54 & 189.30 \\
\hline Sirsa & 176.90 & 179.64 & 182.05 & 179.00 & 179.50 & 173.67 & 181.31 & 183.67 & 182.87 & 184.36 & 4.21 & 1.82 & 180.30 \\
\hline Total & $179.16^{\wedge}$ & $178.61^{\wedge}$ & $177.43^{\wedge}$ & $176.27^{\wedge}$ & 178.85 & 175.68 & 180.13 & 180.81 & 179.88 & 183.02 & 2.15 & 1.22 & 178.98 \\
\hline
\end{tabular}

Source: Computed from various issues of Statistical Abstract of Haryana

Note: n.a. =data not available

^computation excluding 'n.a.' of Palwal and Mewat,c.v.= coeffieient of variation 


\section{Relationship between Cropping Intensity and Irrigation}

Cropping intensity is influenced by many factors such as irrigation, rainfall, use of fertilizers and availability of labour. But the present study is concerned to analyse the relation and impact of irrigation ratio on cropping intensity.

Model (simple linear regression)

$\mathrm{X}_{1 \mathrm{i}}=\alpha+\beta . \mathrm{X}_{2 \mathrm{i}}+\mathrm{C}$

$\mathrm{X}_{1 \mathrm{i}}=$ Cropping Intensity in the $\mathrm{i}^{\text {th }}$ year; $\mathrm{X}_{2 \mathrm{i}}=$ Irrigation Ratio in the $\mathrm{i}^{\text {th }}$ year

$\mathrm{i}=$ Years 2004-05, 2005-06, 2006-07, 2007-08, 2008-09,2009-10, 2010-11, 2011-12 and 2012-13and 2013-14

$\alpha=$ Intercept

$\beta=$ Regression Coefficient

$\mathrm{E}=$ Error term

Cropping Intensity $(\%)=\frac{\text { Total Cropped Area }}{\text { Net Area Sown }} \times 100$,

Irrigation Ratio $(\%)=\frac{\text { Gross Irrigated Area }}{\text { Net Area Sown }} \times 100$

IV. Results

\begin{tabular}{|l|l|l|l|l|l|l|}
\hline Year & R square & Durbin Watson & $\alpha$ & $\beta$ & t value & p-value \\
\hline $2004-05$ & $.24^{*}$ & 2.24 & $139.91^{*}$ & $.26^{*}$ & 2.36 & .030 \\
\hline $2005-06$ & $.24^{*}$ & 1.72 & $136.86^{*}$ & $.28^{*}$ & 2.32 & .033 \\
\hline $2006-07$ & $.18^{* *}$ & 1.73 & $144.78^{* *}$ & $.22^{* *}$ & 1.92 & .071 \\
\hline $2007-08$ & $.36^{*}$ & 1.58 & $127.75^{*}$ & $.32^{*}$ & 3.06 & .007 \\
\hline $2008-09$ & $.31^{*}$ & 1.73 & $132.01^{*}$ & $.31^{*}$ & 2.74 & .014 \\
\hline $2009-10$ & $.47^{*}$ & 1.13 & $118.31^{*}$ & $.37^{*}$ & 3.89 & .001 \\
\hline $2010-11$ & $.35^{*}$ & 1.16 & $129.56^{*}$ & $.33^{*}$ & 3.03 & .008 \\
\hline $2011-12$ & $.34^{*}$ & 1.44 & $135.68^{*}$ & $.29^{*}$ & 2.97 & .009 \\
\hline $2012-13$ & $.34^{*}$ & 1.91 & $127.31^{*}$ & $.33^{*}$ & 2.93 & .009 \\
\hline $2013-14$ & $.25^{*}$ & 2.16 & $143.19^{*}$ & $.25^{*}$ & 2.41 & .028 \\
\hline
\end{tabular}

*represent significant at $5 \%$ level

**represent significant at $10 \%$ level

The regression coefficient is found to be positive at five percent significance level indicating moderate level positive impact of irrigation on cropping intensity. The value of $\mathrm{R}$ square has slightly improved from 2004-05(.24) to 2013-14(.25).It indicates that now 25\% of variation in cropping intensity is explained by the irrigation ratio.However minimum $\mathrm{R}$ square value is observed in 2006-07(.18) and contrary to it, highest value is found in 2009-10(.47).Higher the value of $\mathrm{R}$ square better proportion of outcome is explained by the predictor variable.Similarly trend of $\beta$ coefficient is increasing with highest value of .37(2009-10) which indicates that cropping intensity have an increase of $0.37 \%$ due to one percentincrease in irrigation ratio. Regression coefficient is positive (ranging from .22 to .37) with five percent significance over the years except for 200607(i.e. sig. at ten percent level).It can be seen that b-value is significant (sig. <.05) so irrigation ratio variable significantly predicts the cropping intensity variable. It shows that irrigation ratio has a moderate level positive impact on cropping intensity. For the year 2006-07, insignificant impact may be due to comparatively more influence of other factors such as use of fertilizers, modern equipments and rainfall and availability of labour.Durbin Watson value indicates autocorrelation in the variables. The values approaching to 2 indicate low autocorrelation while approaching to 4 indicates negativeautocorrelation.Durbin Watson valueover the period under study lies between 1.5 and 2.5(except 1.13 in 2009-10 and 1.16 in 2010-11) which indicates absence of autocorrelation. While alow autocorrelationwas found in 2009-10 and 2010-11 in time series data under study. It means that present cropping intensity have low positive autocorrelation with the past year cropping intensity.

\section{Conclusion}

Intensity of croppingin Haryana has been increasing withfluctuatinggrowth rate over the period. Variations are found among districts in intensification of crops. Districts having high average cropping intensity over the years and less fluctuation with steady and positive growth rate are termed to be better performers and vice-versa. Districts in north eastern region of Haryana i.e. Panipat and Karnal district were the highest performers in cropping intensity. Similarly medium performance was observed in Fatehabad and Sirsa district of south western region.On the other hand, districts of southern region i.e. Gurgaon and Jhajjar district had low performance. Such variation occurs because the north eastern region of Haryana is rich in natural resources i.e. rainfall, climate and soil fertility in comparison to the Southern part. However enhancement of cropping intensity is possible by improved irrigation facilities, use of proper fertilizers, seeds and adoption of modern agricultural techniques and by improving the cropping pattern. The irrigation ratio has a moderate level positive 
impact on cropping intensity as supported by the results of analysis in the study. So proper irrigation facility must be ensured to achieve and retain better cropping intensity. Overall performance of Haryana is satisfactory in intensification of cropping except Gurgon, Jhajjar, Rewari and Mewat districts. Government and associated institutions must take steps to improve the irrigation facilities and agricultural inputs to enhance the cropping intensity of poor performing districts and reduce disparity among regions.

\section{References}

[1]. Aggarwal, P. K., \& Moudgil, A. (2015). Structural change and growth of agriculture in Haryana. International Journal of Applied Research, 1 (13), 133-139.

[2]. Hajare, R., Jaykar, T., Patil, V., \& Magdum, A. (2014). Land use and cropping pattern in Kolhapur district. Online International Interdisciplinary Research Journal, 4, 342-348.

[3]. Kalaiselvi, S., \& Sundar, I. (2011). Interstate disparity in cropping intensity in India. International Journal of Business Management, Economics and Information Technology, 3 (2), 269-273.

[4]. Kaunakaran, K., \& Palanisami, K. (1998). An analysis of impact of irrigation on cropping intensity in Tamil Nadu. Indian Economic Review, 33 (2), 207-220.

[5]. Kumar, A., \& Jain, R. (2013). Growth and instability in agricultural productivity: A district level analysis. Agricultural Economics Research Review, 26, 31-42.

[6]. Nag, A., S.K.Kulshrestha, \& Sinha, N. (2009). Growth of cropping intensity in Rajasthan: District wise variation. Annals of Experiment Agriculture \& Allied Sciences, 4 (1 \& 2), 65-68.

[7]. Panigrahy, S., Ray, S., Sood, A., Patel, L., Sharma, P., \& Parihar, J. (2004). Analysis of cropping pattern changes in Bathinda district, Punjab. Journal of the Indian Society of Remote Sensing, 32 (2).

[8]. Raman, R., \& Kumari, R. (2012). Regional disparity in agricultural development: A district-level analysis for Uttar Pradesh. Journal of Regional Development and Planning, 1 (2), 71-90.

[9]. Singh, R. (2015). Analysis of spatial-temporal changes in cropping pattern and cropping intensity in agriculture of Haryana. Online International Interdisciplinary Research Journal, 5 (6), 96-104.

[10]. Singh, S. (2012). Agricultural productivity and agricultural intensity in Rohtash district, Bihar. International Journal of Engineering Research \& Technology, 1 (9), 1-11.

[11]. Singh, V. (1990). Regional disparities in agricultural development. New Delhi: Deep and Deep Publications.

\section{Appendix:}

Table3: District-wise irrigation ratio(in \%) in Haryana

\begin{tabular}{|l|l|l|l|l|l|l|l|l|l|l|}
\hline Districts & $2004-05$ & $2005-06$ & $2006-07$ & $2007-08$ & $2008-09$ & $2009-10$ & $2010-11$ & $2011-12$ & $2012-13$ & $2013-14$ \\
\hline Ambala & 137.31 & 147.76 & 140.91 & 141.98 & 143.51 & 143.18 & 176.42 & 176.64 & 176.85 & 173.15 \\
\hline Panchkula & 95.65 & 83.33 & 100.00 & 95.83 & 108.33 & 104.17 & 100.00 & 96.00 & 108.70 & 113.04 \\
\hline Yamuna Nagar & 148.80 & 153.23 & 150.40 & 150.00 & 160.00 & 161.60 & 160.32 & 163.20 & 163.71 & 162.10 \\
\hline Kurukshetra & 184.67 & 180.67 & 177.33 & 183.33 & 182.67 & 188.67 & 168.32 & 182.78 & 175.50 & 185.03 \\
\hline Kaithal & 190.86 & 186.14 & 185.64 & 188.61 & 189.60 & 187.62 & 191.04 & 189.05 & 194.44 & 192.89 \\
\hline Karnal & 197.45 & 196.50 & 193.94 & 194.47 & 207.41 & 196.95 & 195.00 & 198.96 & 198.47 & 197.92 \\
\hline Panipat & 200.00 & 202.20 & 195.74 & 195.83 & 201.05 & 198.95 & 197.92 & 198.96 & 198.95 & 200.00 \\
\hline Sonipat & 184.35 & 200.00 & 179.11 & 186.45 & 190.97 & 190.85 & 209.03 & 186.98 & 187.50 & 192.05 \\
\hline Rohtak & 128.87 & 128.87 & 131.69 & 134.51 & 142.25 & 140.00 & 142.14 & 144.29 & 148.89 & 150.37 \\
\hline Jhajjar & 116.23 & 114.29 & 122.01 & 119.75 & 121.47 & 116.56 & 117.96 & 145.52 & 134.75 & 146.38 \\
\hline Faridabad & 162.16 & 170.34 & 173.91 & 177.59 & 186.49 & 183.78 & 180.56 & 203.13 & 209.68 & 206.67 \\
\hline Gurgaon & 119.39 & 102.04 & 134.52 & 123.81 & 131.33 & 123.81 & 108.54 & 129.63 & 129.63 & 134.57 \\
\hline Rewari & 123.81 & 125.81 & 149.11 & 129.37 & 114.40 & 119.05 & 117.46 & 116.67 & 125.60 & 132.54 \\
\hline Mahendragarh & 98.68 & 103.29 & 99.34 & 96.71 & 93.38 & 100.00 & 89.73 & 95.42 & 100.00 & 98.69 \\
\hline Bhiwani & 109.14 & 97.72 & 100.25 & 107.09 & 103.10 & 108.63 & 108.09 & 117.84 & 111.50 & 113.53 \\
\hline Jind & 167.70 & 187.12 & 186.38 & 188.46 & 183.75 & 186.55 & 189.50 & 194.54 & 192.05 & 194.56 \\
\hline Hisar & 168.25 & 171.57 & 161.14 & 158.65 & 159.65 & 162.65 & 165.17 & 170.48 & 168.77 & 172.97 \\
\hline Fatehabad & 190.28 & 181.78 & 182.67 & 182.67 & 183.93 & 182.14 & 185.71 & 185.27 & 189.19 & 189.64 \\
\hline Sirsa & 161.93 & 165.65 & 168.72 & 165.25 & 166.00 & 167.59 & 170.96 & 175.51 & 175.82 & 175.64 \\
\hline
\end{tabular}

Source: Computed from various issues of Statistical Abstract of Haryana 